\title{
Mutations of SARS-CoV-2 variants of concern escaping Spike-specific T cells
}

Nina Le Bert ${ }^{1}$, Anthony Tan ${ }^{1}$, Kamini Kunasegaran ${ }^{1}$, Adeline Chia ${ }^{1}$, Nicole Tan ${ }^{1}$, Qi Chen ${ }^{1}$, Shou Kit Hang ${ }^{1}$, Martin DC Qui ${ }^{1}$, Bianca SW Chan ${ }^{2}$, Jenny GH Low ${ }^{1,3}$, Barnaby Young ${ }^{4,5,6}$, Kee Chong $\mathrm{Ng}^{2}$, Derrick Wei Shih $\mathrm{Chan}^{2}$, David Chien Lye $\mathrm{e}^{4,5,6,7}$, Antonio Bertoletti ${ }^{1,8 \#}$

${ }^{1}$ Programme in Emerging Infectious Diseases, Duke-NUS Medical School, Singapore ${ }^{2}$ KK Research Centre, KK Women's and Children's Hospital

${ }^{3}$ Department of Infectious Diseases, Singapore General Hospital, Singapore

${ }^{4}$ National Center of Infectious Diseases, Singapore

${ }^{5}$ Department of Infectious Diseases, Tan Tock Seng Hospital, Singapore

${ }^{6}$ Lee Kong Chian School of Medicine, Singapore

${ }^{7}$ Yong Loo Lin School of Medicine, Singapore

${ }^{8}$ Singapore Immunology Network, A*STAR, Singapore

\#Corresponding Author 


\begin{abstract}
The amino acid (AA) mutations that characterise the different variants of concern (VOCs), which replaced the ancestral SARS-CoV-2 Wuhan-Hu-1 isolate worldwide, provide biological advantages such as increased infectivity and partial escape from humoral immunity. Here we analysed the impact of these mutations on vaccination- and infection-induced Spike-specific $\mathbf{T}$ cells. We confirmed that, in the majority of infected or vaccinated individuals, different mutations present in a single VOC (Delta) or a combined mosaic of more than 30 AA substitutions and deletions found in Alpha, Beta, Gamma, Delta and Omicron VOCs cause modest alteration in the global Spike-specific $T$ cell response. However, distinct numerically dominant Spike-specific CD4 and CD8 T cells preferentially targeted regions affected by AA mutations and do not recognise the mutated peptides. Importantly, some of these mutations, such as N501Y (present in Alpha, Beta, Gamma, and Omicron) and L452R (present in Delta), known to provide biological advantage to SARS-CoV-2 in terms of infectivity also abolished CD8 T cell recognition.

Taken together, our data show that while global mRNA vaccine- and infectioninduced Spike-specific T cells largely tolerate the diverse mutations present in VOCs, single Spike-specific T cells might contribute to the natural selection of SARS-CoV-2 variants.
\end{abstract}


Living organisms, including viruses, constantly evolve to adapt to their environment. They acquire random mutations during replication and deleterious or neutral mutations are purged. Mutations that aid to their spread and persistence ${ }^{1}$ and provide a selective advantage become dominant ${ }^{2,3}$.

The current SARS-CoV-2 pandemic illustrates this phenomenon: after an initial year of relative evolutionary stasis, variants have emerged to replace the initial SARS-CoV2 Wuhan-Hu-1 strain ${ }^{2,3}$. In July 2021 SARS-CoV-2 variants of concern (VOCs) declared by the World Health Organization comprised B.1.1.7-Alpha, B.1.351-Beta, P.1-Gamma, B.1.617.2-Delta ${ }^{3}$. From end-November 2021, a new VOC called Omicron was declared and has spread rapidly worldwide ${ }^{4}$.

The selection of these variants likely occurs due to the combined effect of immunological pressure and acquisition of advantages in transmissibility and fitness ${ }^{1,5}$. Amino acid $(A A)$ variations occur throughout the entire genome ${ }^{2,3}$, however, the moststudied mutations are in the Spike protein ${ }^{6-11}$. Some mutations increase binding to the ACE-2 receptor ${ }^{12-14}$, while others reduce antibody neutralization $6,9,11,15$.

In contrast, the role of SARS-CoV-2-specific T cells in selection pressure has been largely discounted, despite scattered observations that mutations can affect $\mathrm{T}$ cell recognition ${ }^{9,12,16,17}$. The main argument is that $T$ cells recognise various epitopes in vaccinated and convalescent individuals ${ }^{7,18,19}$. As such, VOC-mutations are unlikely to alter all of them 7,10 .

This argument is supported by recent reports documenting the ability of Spike-specific T cells to tolerate the high number of mutations present in Omicron ${ }^{20-26}$, and likely the immunological basis of why vaccinations are still highly effective against VOCs in reducing severe COVID-1927.

However, the role for multi-specific antiviral immunity is not involvement in the selection process of VOCs should not be entirely discounted. Both, humoral and cellular immunity are multi-specific ${ }^{28,29}$ and while most VOCs fully escape recognition of monoclonal antibodies ${ }^{6,30}$, their ability to escape serum neutralisation from convalescent or vaccinated individuals was less dramatic 6,15 before the surge of Omicron. In addition, a hierarchy of antiviral efficacy exists within the polyclonal cellular immune response ${ }^{29}$, and thus some mutations might escape the dominant antiviral T cells, similarly to what has been observed for polyclonal antibodies ${ }^{15}$. 


\section{Results}

Breadth of the Spike-specific T cell response

To understand whether Spike-specific T cells uniformly recognise different Spike regions $^{29}$, we designed seven pools of 33-39 overlapping 15-mer peptides covering 180-200 AA long regions (Fig S1A, Table S1). Peptide-reactive cells were quantified by IFN-y ELISpot ex vivo in 35 vaccinated and 31 convalescents individuals. The mean quantity was different (Fig. S1B, S1C), likely reflecting the time of measurement since T cell induction ( 3 versus 12 months, respectively). Yet, important commonalities were detected. First, as already described ${ }^{31}$, we found significant heterogeneity in the quantity of Spike-specific T cells (Fig. S1B, S1C). Second, most of the individuals exhibited T cells recognising all seven distinct peptide pools (Fig. 1A), in line with the reported $\mathrm{T}$ cell multi-specificity $7,18,19$. However, a dominant $\mathrm{T}$ cell response towards a single peptide pool was frequently observed. In 8/35 vaccinated and 9/31 convalescents, with T cells specific for a single pool exceeding $40 \%$ of the total Spikespecific $\mathrm{T}$ cell response (Fig. 1B). The Spike region 886-1085 was the most immunogenic in both vaccinated (65\%) and convalescents (34\%) (Fig. 1C). This region is fairly conserved among different VOCs, but includes the D950N, S982A and T1027I mutations in the Delta, Alpha and Gamma VOCs, respectively, and the mutations S954H, S969K, S981F in Omicron. In $16 \%$ of vaccinated and $19 \%$ of convalescents, a dominant T cell response was observed towards the region 336-510 (Fig. 1C), containing several VOC mutations that affect the receptor binding affinity $\left(\mathrm{N} 501 \mathrm{Y}^{13,14}, \mathrm{~L}^{152 \mathrm{R}^{12}}\right)$, antibody $\left(\mathrm{K} 417^{32}, \mathrm{~T}_{478 \mathrm{~K}^{15}}, \mathrm{E} 484 \mathrm{~K}^{15}\right)$ and $\mathrm{T}$ cells $\left(\mathrm{L} 452 \mathrm{R}^{12}\right)$ recognitions.

\section{Impact of VOC mutations on global Spike-specific T cells}

Next, we tested the effect of the mutations on Spike-specific T cells. First, we aimed to understand in 100 individuals the impact of Delta mutations on Spike-specific T cells induced by BNT162b2 vaccine. We stimulated whole blood with three peptide pools covering the whole Spike protein (253 peptides) and the regions mutated in Delta (24 peptides) with and without the AA-substitutions/deletions (Fig 2A, Table S2).

We measured the magnitude of the Spike-specific $T$ cell response, its proportion targeting peptides affected by AA changes and calculated the reduction when stimulated with peptides containing Delta-specific mutations (Fig. 2B), which was on average $3.9 \%$ (Fig. 2C). The Spike-specific T cell response was not affected in $46 \%$ 
of the vaccinated individuals; $45 \%$ showed less than $10 \%$ reduction and only in $3 \%$ did we observe more than $20 \%$ reduction in Spike-specific T cells (Fig. 2D). Of note, we confirmed in this large population that there is vast heterogeneity of the Spikespecific $\mathrm{T}$ cell response in different individuals (Fig. S2).

Second, we defined the combined impact of the mutations that are characteristic of the Alpha, Beta, Gamma and Delta VOCs on Spike-specific T cells in 33 vaccinated and 29 convalescents (Fig. 2E, Table S2). Note, 10 of these mutations are also characteristic of the newly emergent Omicron VOC ${ }^{4}$ (Table S3). The combined effect of 30 AA mutations was tested with IFN-y ELISpot assays.

This combination of $30 \mathrm{AA}$ mutations reduced the $\mathrm{T}$ cell response on average by $11.9 \%$ (vaccinated, Fig $2 \mathrm{~F}$ ) and $15.6 \%$ (convalescent, Fig $2 \mathrm{G}$ ), a greater reduction than that detected for the Delta mutations alone (3.9\%). Spike-specific T cells were not affected in $7 / 33$ (21\%) mRNA vaccinated (Fig. $2 \mathrm{H}$ ) and 5/29 (17\%) convalescent individuals (Fig. $2 \mathrm{l}$ ). Less than $10 \%$ reduction was observed in $39 \%$ of vaccinated and $24 \%$ of convalescents. Only in 1 individual of both groups did the combined VOC mutations reduce the Spike-specific T cells by $50 \%$.

Definition of single-peptide specificities of dominant and subdominant Spike-specific $T$ cells

Next, we characterized epitope-specificity and CD4/CD8 phenotype of vaccine- and infection-induced $T$ cells. We utilized an unbiased approach, based on PBMC stimulation with a single peptide pool covering whole Spike and expansion of specific $T$ cells. The $T$ cell lines were then used to confirm the single-peptide specificity, define the phenotype of the responsive T cell (CD4/CD8) and, in selected cases, their HLAClass I restriction (Fig. S3-5). This approach allowed us to define the dominant $\mathrm{T}$ cell specificities, irrespective of the HLA-Class I and Class II profile of the tested individuals.

First, we showed that the expansion procedure preserved the overall hierarchy of Spike-specific $T$ cell recognition detected ex vivo in most of the tested individuals and it was remarkably stable across different time points (Fig. 3SB).

Subsequently, we defined the single peptide specificity and the CD4/CD8 phenotype of $T$ cells in nine vaccinated (Fig. S3C) and 11 convalescents (Fig. S4). Eighteen distinctive Spike-specific CD4 epitopes and 17 different CD8 epitopes were characterized (Fig. S3C, S4; Table1). HLA-Class I restriction of 6 distinct CD8 T cell 
lines was identified utilizing EBV-B cell lines with shared/non-shared HLA-Class I molecules (Fig. S5).

Surprisingly, among the defined peptides containing epitopes targeted by Spikespecific T cells, 12/18 CD4 T cells and 10/17 CD8 T cells recognized peptides that contain 30 out of the 55 distinct AA mutations characteristic of the five VOCs (Table 1, Table S2).

\section{Mutations affecting Spike-specific T cells}

The impact of the AA mutations affecting the peptide-specific $T$ cells was analysed both directly ex vivo (Fig. 3A) and in T cell lines (Fig. S6). We tested 6 CD8 and 5 CD4 $T$ cell specificities containing AA mutations. PBMCs of the individuals in whom the $T$ cell specificities were defined were stimulated in parallel with peptides containing either the wildtype or the mutated AA sequence.

All AA mutations affected the $T$ cell recognition with the partial exception of mutation T1027I present in S1016-30. This mutation altered T cell recognition in one out of two individuals tested. HLA-restriction (Fig. S5) and visualization with HLA-pentamer on the individual who tolerated T1027I (Fig. S7) showed that the T cells were B40restricted and recognized the epitope S1016-1024, which lay outside of the mutations. The ability of the other AA mutations to inhibit $T$ cell recognition strongly suggest that they were located within the T cell epitopes. Mutations affected both CD4 (i.e. S76-90, S206-25, S236-50) and CD8 T cell responses (i.e. S411-25, S446-60, S491-510). Of note, peptide S26-40 stimulated a CD4 and a CD8 T cell response in two different convalescents, suggesting this peptide contains two distinct epitopes. P26S strongly inhibited both CD4 and CD8 T cells.

Of particular interest, we demonstrated that HLA-A*02:05-restricted CD8 T cells specific for the peptide 411-25 were completely inhibited by Beta and Omicron mutation K417N and by Gamma mutation K417T. Moreover, we observed that the mutations L452R and N501Y, which have negligible effect on antibody recognition 33,34 but increase the infectivity of the Delta ${ }^{12}$ and Beta/Gamma ${ }^{13,14}$ VOCs respectively, clearly inhibited recognition of CD8 $T$ cells specific for the HLA-A*24:02 epitope GNYNYLYRLF and HLA-B*15:27 epitope FQPTNGVGY. 
Impact of L452R and N501Y on Spike-specific T cells

The observation that L452R and N501Y, present in Delta (L452R), Alpha, Beta, Gamma and Omicron (N501Y), respectively, increase infectivity ${ }^{12}$ and concomitantly abolish CD8 T cell recognition prompted us to analyse these CD8 T cells in more detail.

The region S446-60 contains the HLA-A*24:02 epitope 448-56 (NYNYLYRLF), has been shown by Motozono et $\mathrm{al}^{12}$ to induce a dominant CD8 $\mathrm{T}$ cell response in convalescents and to be inhibited by L452R. Here we demonstrated that S448-56specific CD8 $T$ cells are also elicited in $A^{*} 24: 02+$ vaccinated individuals and we confirmed the HLA-A*24:02 restriction (Fig. S5).

We then tested the ability of $L 452 R$ to inhibit $T$ cell activation in comparison with other reported AA mutations that affect the Spike region 446-60, namely L452M, Y453F, L455F and G446V (Fig. 3B,C). The mutation Y453F was characteristic of the SARSCoV-2 strain infecting minks ${ }^{35}$, while L452M, Y453F, L455F and G446V, have been occasionally detected $^{36}$. CD8 T cell lines specific for Spike 446-60 were generated in three different HLA-A*24:02+ individuals and we tested the impact of the 5 distinctive AA substitutions. L452R abolished the CD8 T cell recognition almost completely in all the three individuals, followed by L455F, while the other AA substitutions (G446V, L452M, Y453F) were better tolerated (Fig. 3B,C).

To characterize the HLA-B*15:27 restricted CD8 T cell response to the Spike region containing the mutation N501Y, we engineered T cell receptor (TCR)-redirected T cells. The alpha and beta TCR chains of T cells activated by peptide 491-505 were sequenced and cloned into a pVAX1 vector, which allowed the expression of the introduced TCR in allogenic PBMC (Fig 3D). The TCR-redirected T cells were used to define the short epitope (FQPTNGVGY; Fig. 3E) and we confirmed the ability of N501Y to completely abolish CD8 T cell recognition (Fig. 3F). Titration of the peptide concentration used for $\mathrm{T}$ cell activation demonstrated the high affinity of the TCR, a concentration as low as $0.1 \mathrm{ng} / \mathrm{ml}$ induced a response which plateaued at $1 \mu \mathrm{g} / \mathrm{ml}$ (Fig. $3 G)$. 


\section{Discussion}

We designed experiments to address two questions: whether VOCs can escape the global Spike-specific T cell response induced by infection or vaccination and whether T cells can play a role in VOCs selection.

We confirmed the marked multi-specificity of Spike-specific T cells. Although we observed a hierarchy among the $\mathrm{T}$ cells recognizing different Spike regions, the dominant Spike-specific T cells rarely occupied more than $40 \%$ of the repertoire. Furthermore, the region 886-1085 that is preferentially targeted by T cells contains few mutations present in Alpha (S982A), Gamma (T1027) and Delta (D950N) ${ }^{15}$ and also in the newly emerged Omicron VOC (S954H, S969K, S981F) 4 .

The broad multi-specificity translated into the functional ability to largely tolerate $A A$ substitution present in different VOCs. This was first observed in a large population of mRNA vaccinated individuals $(n=100)$. In $91 \%$ of them, the effect of mutations present in Delta, inhibited Spike-specific T cells by less than $10 \%$. Second, when we tested the combined effect of 30 distinct AA substitutions/deletions (mutations found in Alpha, Beta, Gamma and Delta VOCs, of which 10 have also been detected in Omicron), we found that convalescent or vaccinated individuals of Asian origin possess Spikespecific $T$ cells that largely tolerate the combined AA substitutions. These data agree with the recent reports of the substantial, although not absolute, preservation of global Spike-specific T cell response against the highly mutated Omicron ${ }^{20-26}$.

Our data however reveals novel important features of the Spike-specific cellular immunity. In addition to the detection of a broad heterogeneity in the magnitude of the T cell response, we demonstrated that 12 distinct AA substitutions of VOCs alter 11 individual $T$ cell specificities characterized in a relatively small number of vaccinated and convalescent individuals $(n=20)$. VOC mutations affect the activation of CD8 and CD4 $\mathrm{T}$ cells and mutations already known to abrogate antibody recognition like K417N ${ }^{34}$ (present in Beta and Omicron VOC) or K417T and D138Y (present in Gamma VOC) $)^{8}$ also inhibit Spike-specific CD8 T cells.

Remarkably, we observed that mutations L452R (present in Delta) and N501Y (present in Alpha, Beta Gamma and Omicron), which have negligible effect on the neutralization ability of polyclonal sera ${ }^{33,34}$, but increase the binding affinity of Spike protein to the ACE2 receptor ${ }^{12-14}$, abolish the recognition of CD8 T cells specific for 
one HLA-A*24:02 (S447-56) and one HLA-B*15:27 (S497-505)-restricted epitope. This convergence of biological effects is reminiscent of the hypothesis of the causes of influenza hemagglutinin variant selection. In animal models of Influenza, antibodies select viruses with mutations that provide a generalized advantage by increasing receptor avidity ${ }^{5}$.

In general, immune escape mutations affecting $\mathrm{T}$ cell epitopes are selected in individuals with chronic viral infections (i.e. HIV, HBV, HCV, HDV, HCMV, EBV) ${ }^{37}$ but are unlikely to uniformly affect the wider human population. Since the biology of T cell recognition makes the $\mathrm{T}$ cell repertoire largely unique for each individual ${ }^{29}$, it is unlikely that a virus variant with a single set of immune escape mutations will affect the whole human population identically and successfully spread globally. However, if mutations permit escape from a specific $\mathrm{T}$ cell specificity in parallel with increasing the receptor binding affinity of Spike, as in the case of L452R and N501Y, such advantage will no longer be solely restricted to a selected population. Interestingly, recent mathematical models of SARS-CoV-2 variant spread suggested that mutations able to concurrently increase infectivity and immune escape are likely to rapidly propagate in the population $^{38}$.

Our data do not provide the demonstration that this chain of events took place during this pandemic. Nevertheless, they indicate an alternative possibility to the prevalent theory that postulates that VOCs emerged exclusively under the pressure of neutralizing antibodies.

We made the unexpected observation that a large number of T cells (20 out of 35) selected in vitro by PBMC stimulation with whole Spike peptide pool recognized peptides carrying the VOC mutated regions of Spike. This is at odds with ex-vivo results obtained by us and others, since $\mathrm{T}$ cells specific for variant regions represent a minority of the global Spike $T$ cell repertoire in the ex vivo analysis ${ }^{7,18-26}$. One might speculate that the in vitro expansion mimics the immunological events occurring after SARS-CoV-2 infection and, as such, the analysis of $\mathrm{T}$ cells after in vitro expansion selects for the dominant effector $\mathrm{T}$ cell response present during the acute phase of response. These dominant $\mathrm{T}$ cells might thus exert higher selective pressure. Future studies will be necessary to verify the robustness of the observation and its real mechanisms. However, by determining HLA-restrictions of a number of these $T$ cell 
epitopes targeting mutated regions (at least for HLA-Class I), we provide the possibility to test whether, for example, breakthrough infection might occur more frequently in individuals with such HLA-Class I profiles. Finally, the demonstration that AA mutations escaping specific CD8 $T$ cells and concomitantly offer the virus a biological advantage in term of increased infectivity ${ }^{14}$, provides the theoretical possibility that $\mathrm{T}$ cell pressure might contribute to the selection of VOCs.

There are some limitations to this study. We tested the impact of AA substitutions on Spike-specific T cells utilizing peptide-pulsed target cells and not infected cells. This method might overestimate the quantity of $T$ cells specific for SARS-CoV-2 because low affinity $T$ cells might have been quantified and be more sensitive to $A A$ mutations. On the other hand, peptide-pulsed target cells cannot be used to evaluate the impact that AA substitutions might have on the processing of T cell epitopes ${ }^{37}$. AA outside the T cell epitopes can alter their generation ${ }^{39}$ and as such we might have underestimate the impact of the mutations on the Spike-specific cellular immunity. 


\section{References}

1. Duffy, S., Shackelton, L. A. \& Holmes, E. C. Rates of evolutionary change in viruses: patterns and determinants. Nat Rev Genet 9, 267-276 (2008).

2. Harvey, W. T. et al. SARS-CoV-2 variants, spike mutations and immune escape. Nat Rev Microbiol 19, 409-424 (2021).

3. Dorp, L. van, Houldcroft, C. J., Richard, D. \& Balloux, F. COVID-19, the first pandemic in the post-genomic era. Curr Opin Virol 50, 40-48 (2021).

4. Viana, R. et al. Rapid epidemic expansion of the SARS-CoV-2 Omicron variant in southern Africa. Nature (2022) doi:10.1038/d41586-021-03832-5.

5. Hensley, S. E. et al. Hemagglutinin Receptor Binding Avidity Drives Influenza A Virus Antigenic Drift. Science 326, 734-736 (2009).

6. Collier, D. A. et al. Sensitivity of SARS-CoV-2 B.1.1.7 to mRNA vaccine-elicited antibodies. Nature 593, 136-141 (2021).

7. Geers, D. et al. SARS-CoV-2 variants of concern partially escape humoral but not T-cell responses in COVID-19 convalescent donors and vaccinees. Sci Immunol 6, eabj1750 (2021).

8. Garcia-Beltran, W. F. et al. Multiple SARS-CoV-2 variants escape neutralization by vaccine-induced humoral immunity. Cell 184, 2372-2383.e9 (2021).

9. Reynolds, C. J. et al. Prior SARS-CoV-2 infection rescues B and T cell responses to variants after first vaccine dose. Science 372, 1418-1423 (2021).

10. Alter, G. et al. Immunogenicity of Ad26.COV2.S vaccine against SARS-CoV-2 variants in humans. Nature 1-5 (2021) doi:10.1038/s41586-021-03681-2.

11. Planas, D. et al. Sensitivity of infectious SARS-CoV-2 B.1.1.7 and B.1.351 variants to neutralizing antibodies. Nat Med 27, 917-924 (2021).

12. Motozono, C. et al. SARS-CoV-2 spike L452R variant evades cellular immunity and increases infectivity. Cell Host Microbe 29, 1124-1136.e11 (2021).

13. Starr, T. N. et al. Deep Mutational Scanning of SARS-CoV-2 Receptor Binding Domain Reveals Constraints on Folding and ACE2 Binding. Cell 182, 1295-1310.e20 (2020).

14. Liu, Y. et al. The N501Y spike substitution enhances SARS-CoV-2 infection and transmission. Nature 1-9 (2021) doi:10.1038/s41586-021-04245-0. 
15. Greaney, A. J. et al. Comprehensive mapping of mutations in the SARS-CoV-2 receptor-binding domain that affect recognition by polyclonal human plasma antibodies. Cell Host Microbe 29, 463-476.e6 (2021).

16. Silva, T. I. de et al. The impact of viral mutations on recognition by SARS-CoV-2 specific T cells. Iscience 24, 103353 (2021).

17. Agerer, B. et al. SARS-CoV-2 mutations in MHC-I-restricted epitopes evade CD8+ T cell responses. Sci Immunol 6, eabg6461 (2021).

18. Tarke, A. et al. Impact of SARS-CoV-2 variants on the total CD4+ and CD8+ T cell reactivity in infected or vaccinated individuals. Cell Reports Medicine 2, 100355 (2021).

19. Woldemeskel, B. A., Garliss, C. C. \& Blankson, J. N. SARS-CoV-2 mRNA vaccines induce broad CD4+ T cell responses that recognize SARS-CoV-2 variants and HCoV-NL63. J Clin Invest 131, (2021).

20. Gao, Y. et al. Ancestral SARS-CoV-2-specific T cells cross-recognize Omicron (B.1.1.529). (2022) doi:10.21203/rs.3.rs-1217466/v1.

21. GeurtsvanKessel, C. H. et al. Divergent SARS CoV-2 Omicron-specific T- and Bcell responses in COVID-19 vaccine recipients. Medrxiv 2021.12.27.21268416 (2021) doi:10.1101/2021.12.27.21268416.

22. Marco, L. D. et al. Preserved T cell reactivity to the SARS-CoV-2 Omicron variant indicates continued protection in vaccinated individuals. Biorxiv 2021.12.30.474453 (2021) doi:10.1101/2021.12.30.474453.

23. Keeton, R. et al. SARS-CoV-2 spike $T$ cell responses induced upon vaccination or infection remain robust against Omicron. Medrxiv 2021.12.26.21268380 (2021) doi:10.1101/2021.12.26.21268380.

24. Tarke, A. et al. SARS-CoV-2 vaccination induces immunological memory able to cross-recognize variants from Alpha to Omicron. Biorxiv 2021.12.28.474333 (2021) doi:10.1101/2021.12.28.474333.

25. Naranbhai, V. et al. T cell reactivity to the SARS-CoV-2 Omicron variant is preserved in most but not all prior infected and vaccinated individuals. doi:10.1101/2022.01.04.21268586.

26. Liu, J. et al. Vaccines Elicit Highly Cross-Reactive Cellular Immunity to the SARS-CoV-2 Omicron Variant. Medrxiv 2022.01.02.22268634 (2022) doi:10.1101/2022.01.02.22268634.

27. Bernal, J. L. et al. Effectiveness of Covid-19 Vaccines against the B.1.617.2 (Delta) Variant. New Engl J Med (2021) doi:10.1056/nejmoa2108891.

28. Lee, J. M. et al. Mapping person-to-person variation in viral mutations that escape polyclonal serum targeting influenza hemagglutinin. Elife 8, e49324 (2019). 
29. Yewdell, J. W. Confronting Complexity: Real-World Immunodominance in Antiviral CD8+ T Cell Responses. Immunity 25, 533-543 (2006).

30. Chen, R. E. et al. Resistance of SARS-CoV-2 variants to neutralization by monoclonal and serum-derived polyclonal antibodies. Nat Med 27, 717-726 (2021).

31. Bert, N. L. et al. Widely heterogeneous humoral and cellular immunity after mild SARS-CoV-2 infection in a homogeneous population of healthy young men: Heterogenous immunity to SARS-CoV-2. Emerg Microbes Infec 10, 2141-2150 (2021).

32. Barnes, C. O. et al. SARS-CoV-2 neutralizing antibody structures inform therapeutic strategies. Nature 588, 682-687 (2020).

33. Xie, X. et al. Neutralization of SARS-CoV-2 spike 69/70 deletion, E484K and N501Y variants by BNT162b2 vaccine-elicited sera. Nat Med 27, 620-621 (2021).

34. Rees-Spear, C. et al. The impact of Spike mutations on SARS-CoV-2 neutralization. Cell Reports 34, 108890 (2021).

35. Hoffmann, M. et al. SARS-CoV-2 mutations acquired in mink reduce antibodymediated neutralization. Cell Reports 35, 109017 (2021).

36. http://sars2.cvr.gla.ac.uk/cog-uk. COVID-19 Genomics UK Consortium,.

37. Lorenzo, M. E., Ploegh, H. L. \& Tirabassi, R. S. Viral immune evasion strategies and the underlying cell biology. Semin Immunol 13, 1-9 (2001).

38. Bushman, M., Kahn, R., Taylor, B. P., Lipsitch, M. \& Hanage, W. P. Population impact of SARS-CoV-2 variants with enhanced transmissibility and/or partial immune escape. Cell 184, 6229-6242.e18 (2021).

39. Tenzer, S. et al. Antigen processing influences HIV-specific cytotoxic T lymphocyte immunodominance. Nature Immunology 10, 636-646 (2009). 
bioRxiv preprint doi: https://doi.org/10.1101/2022.01.20.477163; this version posted January 25, 2022. The copyright holder for this preprint (which was not certified by peer review) is the author/funder, who has granted bioRxiv a license to display the preprint in perpetuity. It is made available under aCC-BY-NC-ND 4.0 International license.

Table 1: Details of identified Spike-specific $T$ cell specificities

\begin{tabular}{|c|c|c|c|c|c|c|}
\hline T cell & Sample & Peptides & Sequence & VOC Mutations & Dominant & HLA \\
\hline \multirow{19}{*}{$\stackrel{0}{0}$} & \multirow{13}{*}{ 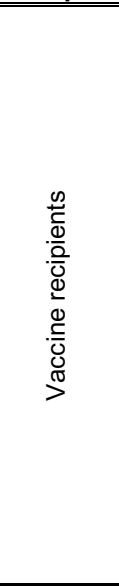 } & $81-95$ & NPVLPFNDGVYFAST & T95I & yes & $B * 35: 01$ \\
\hline & & $131-145$ & CEFQFCNDPFLGVYY & $\begin{array}{l}\text { D138Y, G142D } \\
\Delta 144, \Delta 143-5\end{array}$ & & \\
\hline & & $266-280$ & YVGYLQPRTFLLKYN & & yes & $A^{*} 02: 01$ \\
\hline & & $346-360$ & RFASVYAWNRKRISN & & & \\
\hline & & $360-375$ & KRISNCVADYSVLYN & S371L & & \\
\hline & & $375-390$ & SASFSTFKCYGVSPT & & & \\
\hline & & $411-425$ & APGQTGKIADYNYKL & $\mathrm{K} 417 \mathrm{~T}, \mathrm{~K} 417 \mathrm{~N}$ & yes & $A^{*} 02: 05$ \\
\hline & & $446-460$ & GGNYNYLYRLFRKSN & L452R & yes & $A^{*} 24: 02$ \\
\hline & & $491-505$ & PLQSYGFQPTNGVGY & $\begin{array}{l}\text { Q493R, G496S, } \\
\text { Q498R, N501Y, } \\
\text { Y505H }\end{array}$ & yes & $B^{*} 15: 27$ \\
\hline & & $641-655$ & NVFQTRAGCLIGAEH & H655Y & & \\
\hline & & $681-695$ & PRRARSVASQSI IAY & $\mathrm{P} 681 \mathrm{H}, \mathrm{P} 681 \mathrm{R}$ & & \\
\hline & & $1016-1030$ & AEIRASANLAATKMS & T1027I & yes & $B^{*} 40: 01$ \\
\hline & & $1051-1065$ & SFPQSAPHGVVFLHV & & & $\mathrm{B}^{*} 54: 01$ \\
\hline & \multirow{6}{*}{ 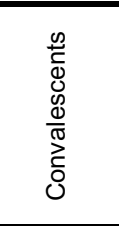 } & $26-40$ & PAYTNSFTRGVYYPD & $\mathrm{P} 26 \mathrm{~S}$ & yes & \\
\hline & & $281-295$ & ENGTITDAVDCALDP & & yes & \\
\hline & & $421-435$ & YNYKLPDDFTGVIA & & yes & \\
\hline & & $446-460$ & GGNYNYLYRLFRKSN & L452R & yes & $A^{*} 24: 02$ \\
\hline & & $1001-1015$ & LQSLQTYVTQQLIRA & & & \\
\hline & & $1051-1065$ & SFPQSAPHGVVFLHV & & yes & $B^{*} 54: 01$ \\
\hline \multirow{23}{*}{ 苍 } & \multirow{11}{*}{ 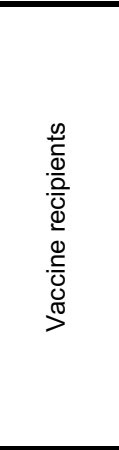 } & $211-230$ & NLVRDLPQGFSALEPLVDLP & $\begin{array}{l}\text { N211I, } \\
\Delta 221, \text { EPE214, } \\
\text { D215G }\end{array}$ & yes & \\
\hline & & $236-250$ & TRFQTLLALHRSYLT & $\Delta 241-3$ & & \\
\hline & & $416-440$ & GKIADYNYKLPDDFTGCVIAWNSNN & K417N， K417T & & \\
\hline & & $446-465$ & GGNYNYLYRLFRKSNLKPFE & L452R & & \\
\hline & & $556-570$ & NKKFLPFQQFGRDIA & A570D & yes & \\
\hline & & $896-920$ & IPFAMQMAYRFNGIGVTQNVLYENQ & & yes & \\
\hline & & $931-950$ & IGKIQDSLSSTASALGKLQD & D950N & & \\
\hline & & $976-1000$ & VLNDILSRLDKVEAEVQIDRLITGR & L981F, S982A & & \\
\hline & & $1006-1020$ & LQSLQTYVTQQLIRAAEIRA & & & \\
\hline & & $1051-1075$ & SFPQSAPHGVVFLHVTYVPAQEKNF & & & \\
\hline & & $1095-1120$ & VSNGTHWFVTQRNFYEPQI ITTDNT & D1118H & yes & \\
\hline & \multirow{12}{*}{ 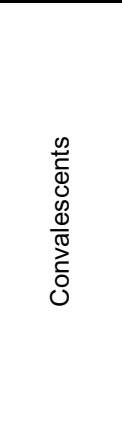 } & $26-40$ & PAYTNSFTRGVYYPD & P26.S & & \\
\hline & & $76-90$ & TKRFDNPVLPFNDGV & $\mathrm{D} 80 \mathrm{~A}$ & yes & \\
\hline & & $201-220$ & FKIYSKHTP INLVRDLPQG & N211I, & & \\
\hline & & & & $\begin{array}{l}\Delta 221, \operatorname{EPE} 214, \\
\mathrm{D} 215 \mathrm{G}\end{array}$ & & \\
\hline & & $311-325$ & GIYQTSNFRVQPTES & & yes & \\
\hline & & $411-430$ & APGQTGKIADYNYKLPDDFT & K417N， K417T & & \\
\hline & & $446-460$ & GGNYNYLYRLFRKSN & L452R & & \\
\hline & & $556-570$ & NKKFLPFQQFGRDIA & A570D & & \\
\hline & & $921-940$ & KLIANQFNSAIGKIQDSLSS & & yes & \\
\hline & & $931-945$ & IGKIQDSLSSTASAL & & & \\
\hline & & $956-970$ & AQALNTLVKQLSSNF & & & \\
\hline & & $1016-1030$ & AEIRASANLAATKMS & T1027I & & \\
\hline
\end{tabular}




\section{Methods:}

Ethics statement: All donors provided written consent. The study was conducted in accordance with the Declaration of Helsinki and approved by the NUS institutional review board (H-20-006) and the SingHealth Centralised Institutional Review Board (reference $\mathrm{CIRB/F/2018/2387).}$

Human samples: Donors were recruited based on their clinical history of SARS-CoV2 infection and their vaccination status. Blood samples of recovered COVID-19 patients $(n=35)$ were obtained 6-12 months post PCR negativity. Blood samples of two vaccinated cohorts were taken, 35 donors were recruited at multiple timepoints until 3 months post second dose BNT162b, and additional 100 donors at 9 months post second dose BNT162b. Vaccinated individuals were all healthy adults, 20-65 years old, of Asian origin.

PBMC isolation: Peripheral blood mononuclear cells (PBMC) were isolated by density-gradient centrifugation using Ficoll-Paque. Isolated PBMC were either studied directly or cryopreserved and stored in liquid nitrogen until used in the assays.

Peptide pools: 15-mer peptides overlapping by 10 amino acids spanning the entire protein sequence of SARS-CoV-2 Spike were synthesized (GenScript; see Table S1). To stimulate whole blood or PBMC, the peptides were divided into 7 pools of about 40 peptides. For single peptide identification, peptides were organized in a matrix of 16 numeric and 16 alphabetic pools. Peptides with and without VOC mutations were mixed into two separate pools (Table S2).

Cytokine release assay (CRA) from whole peripheral blood: $320 \mu$ l of whole blood drawn on the same day were mixed with $80 \mu \mathrm{LPMI}$ and stimulated with the indicated SARS-CoV-2 Spike peptide pools at $2 \mu \mathrm{g} / \mathrm{ml}$ or with DMSO as a control. After 16 hours of culture, the culture supernatant (plasma) was collected and stored at $-80^{\circ} \mathrm{C}$. Cytokine concentrations in the plasma were quantified using an Ella machine with microfluidic multiplex cartridges measuring IFN-Y and IL-2 following the manufacturer's instructions (ProteinSimple). The level of cytokines present in the plasma of DMSO controls was subtracted from the corresponding peptide pool stimulated samples. The positivity threshold was set at $10 x$ times the lower limit of 
quantification of each cytokine (IFN-ץ $=1.7 \mathrm{pg} / \mathrm{ml} ; \mathrm{IL}-2=5.4 \mathrm{pg} / \mathrm{ml}$ ) after DMSO background subtraction.

ELISpot assay: ELISpot plates (Millipore) were coated with human IFN-Y antibody (1D1K, Mabtech; $5 \mu \mathrm{g} / \mathrm{ml}$ ) overnight at $4^{\circ} \mathrm{C}$. 400,000 PBMC were seeded per well and stimulated for $18 \mathrm{~h}$ with pools of SARS-CoV-1/2 peptides $(2 \mu \mathrm{g} / \mathrm{ml})$. For stimulation with peptide matrix pools or single peptides, a concentration of $5 \mu \mathrm{g} / \mathrm{ml}$ was used. Subsequently, the plates were developed with human biotinylated IFN-y detection antibody (7-B6-1, Mabtech; 1:2000), followed by incubation with Streptavidin-AP (Mabtech) and KPL BCIP/NBT Phosphatase Substrate (SeraCare). Spot forming units (SFU) were quantified with ImmunoSpot. To quantify positive peptide-specific responses, $2 x$ mean spots of the unstimulated wells were subtracted from the peptidestimulated wells, and the results expressed as SFU $/ 10^{6}$ PBMC. We excluded the results if negative control wells had $>30$ SFU $/ 10^{6}$ PBMC or positive control wells (PMA/lonomycin) were negative.

Flow Cytometry: PBMC or expanded T cell lines were stimulated for $5 \mathrm{~h}$ at $37^{\circ} \mathrm{C}$ with or without SARS-CoV-2 peptides $(2 \mu \mathrm{g} / \mathrm{ml})$ in the presence of $10 \mu \mathrm{g} / \mathrm{ml}$ brefeldin $A$ (Sigma-Aldrich). Cells were stained with the yellow LIVE/DEAD fixable dead cell stain kit (Invitrogen) and anti-CD3 (clone SK7; 3:50), anti-CD4 (clone SK3; 3:50), and antiCD8 (clone SK1; 3:50) antibodies. Cells were subsequently fixed and permeabilized using the Cytofix/Cytoperm kit (BD Biosciences-Pharmingen) and stained with antiIFN-Y (clone 25723, R\&D Systems; 1:25) and anti-TNF- $\alpha$ (clone MAb11; 1:25) antibodies and analyzed on a BD-LSR II FACS Scan. Data were analyzed by FlowJo (Tree Star Inc.). Antibodies were purchased from BD Biosciences-Pharmingen unless otherwise stated.

Expanded T cell lines: T cell lines were generated as follows: $20 \%$ of PBMC were pulsed with $10 \mu \mathrm{g} / \mathrm{ml}$ of the overlapping SARS-CoV-2 peptides (all pools combined) or single peptides for 1 hour at $37^{\circ} \mathrm{C}$, subsequently washed, and cocultured with the remaining cells in AIM-V medium (Gibco; Thermo Fisher Scientific) supplemented with $2 \%$ AB human serum (Gibco; Thermo Fisher Scientific). T cell lines were cultured for 10 days in the presence of $20 \mathrm{U} / \mathrm{ml}$ of recombinant IL-2 (R\&D Systems). 
HLA-restriction assay: The HLA-haplotype (4 digit HLA-typing) of individuals was determined and different EBV transformed B cells lines with one common allele each were selected for presentation of the indicated peptides. B cells were pulsed with 10 $\mu \mathrm{g} / \mathrm{ml}$ of the peptide for 1 hour at $37^{\circ} \mathrm{C}$, washed three times, and cocultured with the expanded $\mathrm{T}$ cell line at a ratio of $1: 1$ in the presence of $10 \mu \mathrm{g} / \mathrm{ml}$ brefeldin A (SigmaAldrich). Non-pulsed B cell lines served as a negative control detecting potential allogeneic responses and autologous peptide-pulsed cells served as a positive control.

TCR-redirected SARS-CoV-2-specific CD8+ T cells: Spike-specific T cell line was stimulated for 5 hours with peptide S491-505 and the activated antigen-specific T cells were identified through the expression of CD107a. The CD107a+ T cells were sorted and single cell TCR sequencing was performed and analyzed using the $10 x$ Genomics human T cell V(D)J amplification kit (10x Genomics) according to the manufacturer's recommendations.

Spike 491-510-specific TCR $\alpha$ and $\beta$ chain genes were subcloned into T7 expression vector ( $p$-VAX1), the SARS-CoV-2-TCR mRNA was transcribed in vitro using the mMESSAGE mMACHINE ${ }^{\text {TM }}$ T7 ULTRA Transcription Kit (ThermoFisher Scientitic) following the manufacturer's protocols. To introduce the TCR expression in nonmemory T cells, PBMCs from healthy individuals were isolated and expanded in vitro for 7 days in the presence of $50 \mathrm{ng} / \mathrm{ml}$ of OKT-3 (Miltenyi) and $600 \mathrm{IU} / \mathrm{ml} \mathrm{IL-2} \mathrm{(R \& D}$ Systems) in AIM-V (Gibco) medium supplemented with $2 \%$ human AB serum (Gibco). The concentration of IL-2 was increased to $1000 \mathrm{IU} / \mathrm{ml}$ on day 7 and the expanded T cells were electroporated with the indicated mRNA at a concentration of $2 \mathrm{pg}$ mRNA/cell on day 8 using 4D Nucleofector ${ }^{T M}$ System (Lonza) according to the manufacturer's instructions. Electroporated T cells were rested for 5 mins before been maintained in AIM-V media supplemented with $10 \%$ human $A B$ serum and $100 \mathrm{IU} / \mathrm{ml}$ IL-2 overnight. The expression of the introduced TCR were examined using Live/Dead Fixable Yellow Dead Cell Stain Kit (ThermoFisher Scientific), anti-human TCR V $\beta 1$ (Beckman Coulter), anti-human CD3 and CD8 antibodies (BD Bioscience).

Peptide-pulse experiment: The EBV-transformed lymphoblastoid B (EBV-B) cell lines with identified HLA-B*15:27 phenotype were used as antigen-presenting cells and cocultured with the indicated concentrations of peptides for 1 hour at $37^{\circ} \mathrm{C}$. The 
peptide-pulsed EBV-B cells were washed twice with HBSS (Gibco) before cocultured with the TCR-redirected T cells at a 1:1 ratio in the presence of brefeldin A $(2 \mu \mathrm{g} / \mathrm{ml})$ overnight. The cells were stained with Live/Dead in $1 \times$ PBS for $10 \mathrm{~min}$ at room temperature and then stained with anti-human CD3 and CD8 antibodies for $30 \mathrm{~min}$ at $4^{\circ} \mathrm{C}$. The cells were fixed and permeabilized using the Cytofix/Cytoperm fixation/permeabilization (BD Biosciences) buffer following the manufacturer's protocols. Intracellular cytokine staining was performed with anti-human IFN $\gamma$ and TNF $\alpha$ (BD Biosciences) antibodies for $30 \mathrm{~min}$ at room temperature, followed by washing and analysis by flow cytometry. 


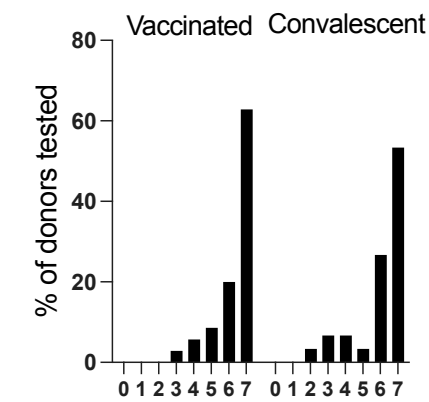

$\mathrm{N}^{\circ}$ of positive Spike-peptide pools

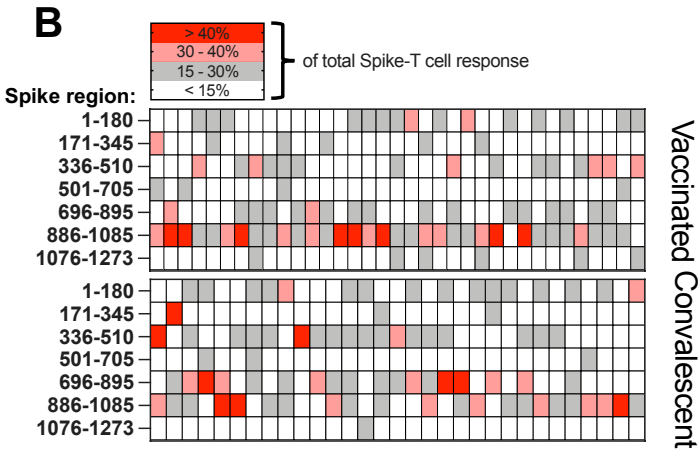

Individuals tested

\section{Dominat $\mathrm{T}$ cell response}

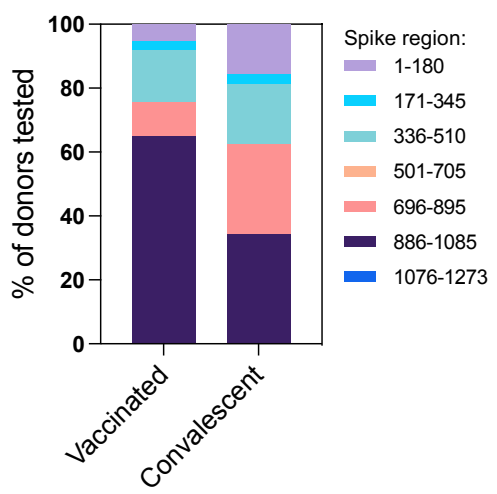

Figure 1: Breath of the Spike-specific T cell response in BNT162b mRNA vaccinated donors and SARS-CoV-2 convalescents.

A. Bar graphs show the percentage of donors (vaccinated $n=35$; convalescent $n=31$ ) reacting to the number of Spikepeptide pools tested (total 7 distinct peptide pools). B. Heatmap is indicating the percentage of the response towards a single peptide pool in proportion to the total Spike-specific response in each of the tested individuals. C, Percentage of tested individuals with a dominant response to one of the 7 peptide pools is shown. 


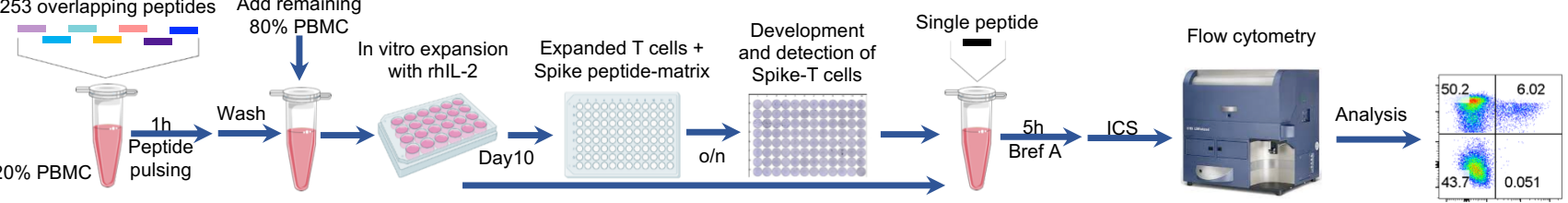

B

B

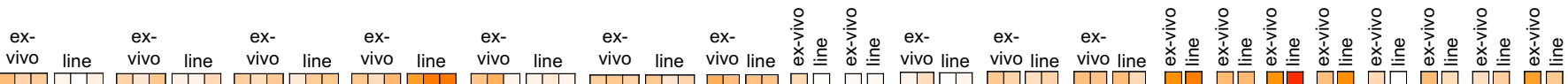

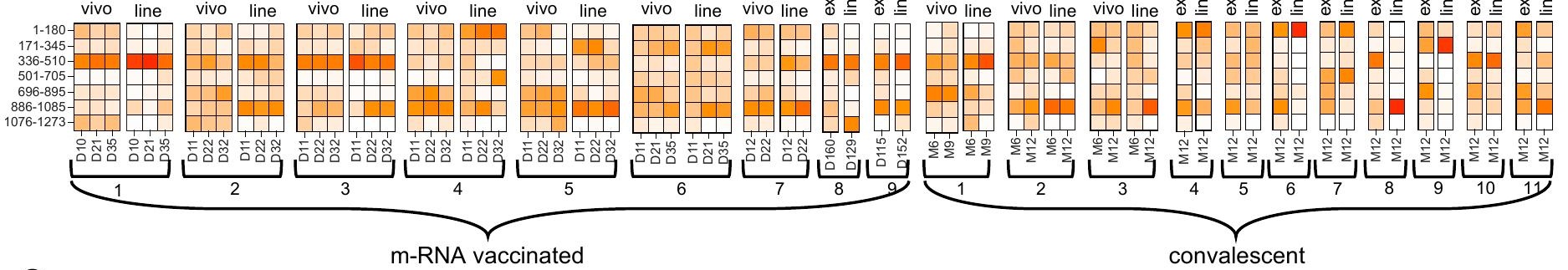

C

m-RNA vaccinated

convalescent

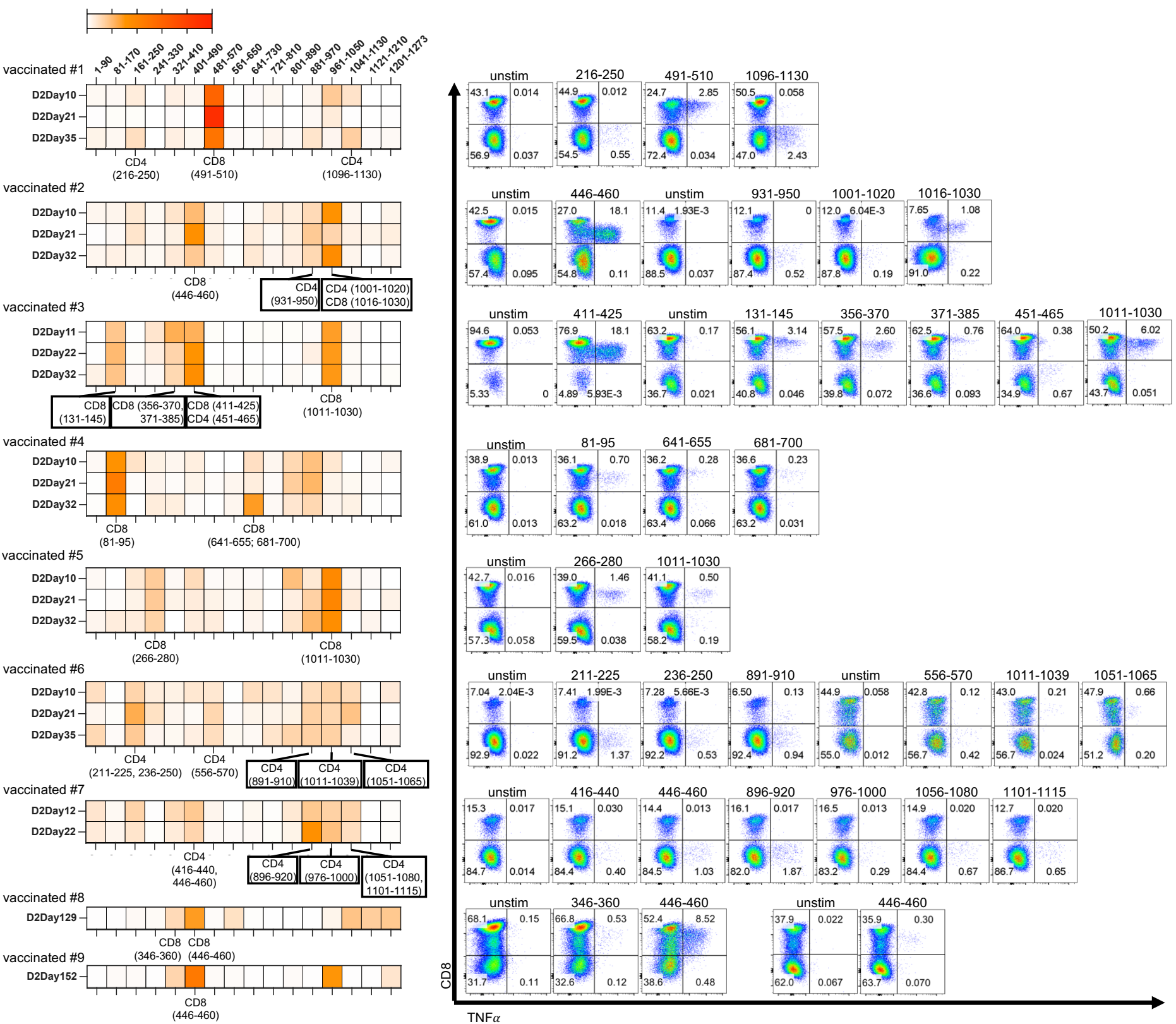

Figure S3: Definition of single-peptide specificities of dominant and subdominant Spike-specific T cells

A, Schematic of Spike-specific short-term T cell line expansion procedure, ELISpot peptide-matrix for identification of putative single peptide responses and their confirmation and phenotype characterisation by intracellular cytokine staining and flowcytometry analysis. B. Side by side comparison of the response hierarchy to the seven individual Spike-peptide pools directly ex vivo and after in vitro expansion. Heatmap represents the percentage of the response to each peptide pool among the total Spike-response. 9 vaccinated donors and 11 convalescents were analysed at multiple timepoints. C, Heatmap of the response of the short-term T cell lines of the 9 vaccinated donors to the numerical pools of the peptide matrix covering 16 distinct regions of the Spike-protein (left). Single-peptide responses were confirmed by ICS (right). 

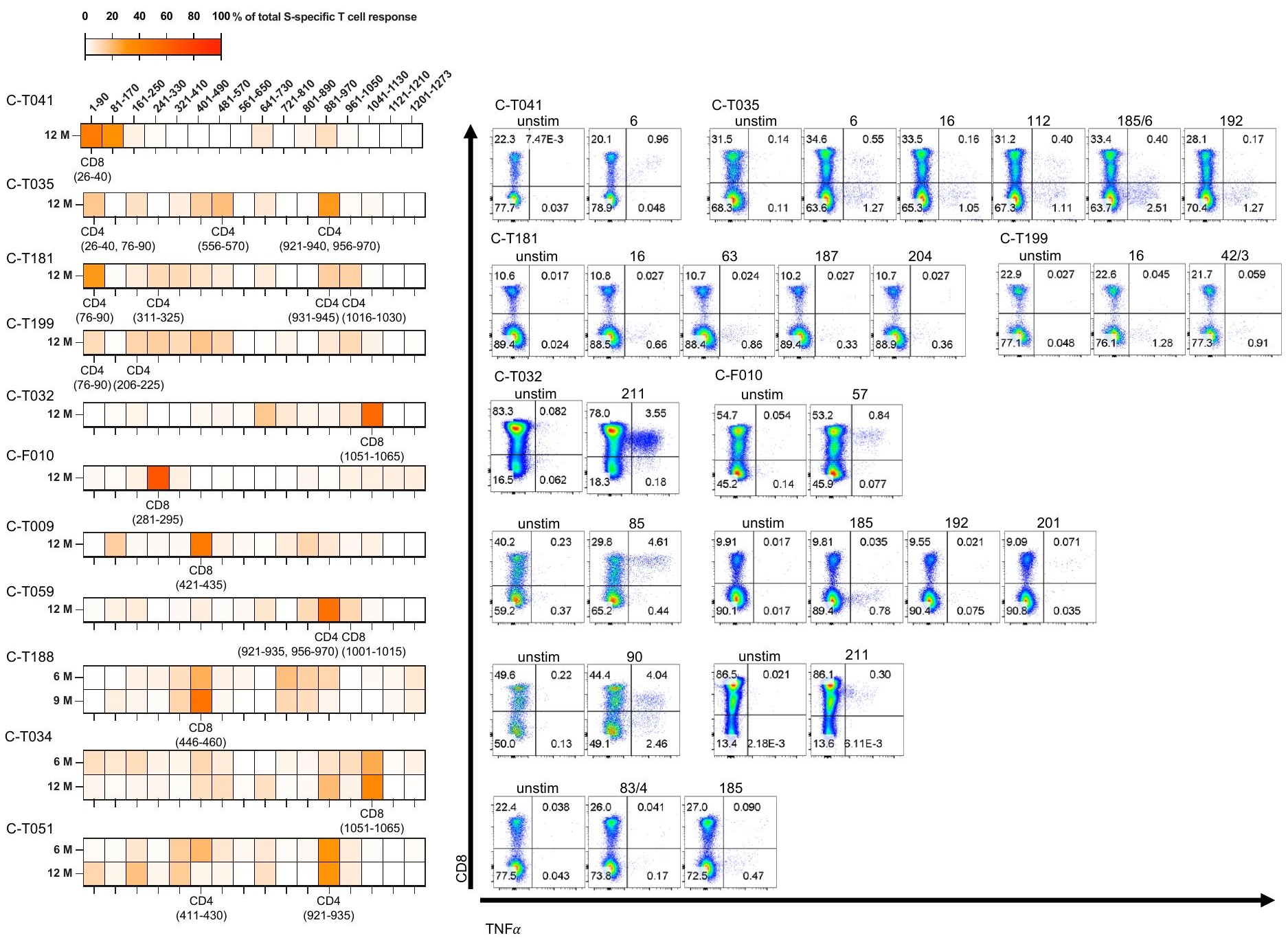

Figure S4: Definition of single-peptide specificities of dominant and subdominant Spike-specific $\mathrm{T}$ cells in SARS-CoV-2 convalescent donors.

Heatmap of the response of the short-term $\mathrm{T}$ cell lines of the 11 convalescent donors to the numerical pools of the peptide matrix covering 16 distinct regions of the Spike-protein (left). Single-peptide responses were confirmed by ICS (right). 


vaccinated \#1
\begin{tabular}{|c|c|c|c|c|c|}
\hline \multicolumn{7}{|c|}{ HLA-Class I haplotype } \\
\hline $\mathrm{A} 1$ & $\mathrm{~A} 2$ & $\mathrm{~B} 1$ & $\mathrm{~B} 2$ & $\mathrm{C} 1$ & $\mathrm{C} 2$ \\
$11: 01$ & $11: 02$ & $15: 27$ & $40: 01$ & $03: 04$ & $04: 01$ \\
\hline
\end{tabular}
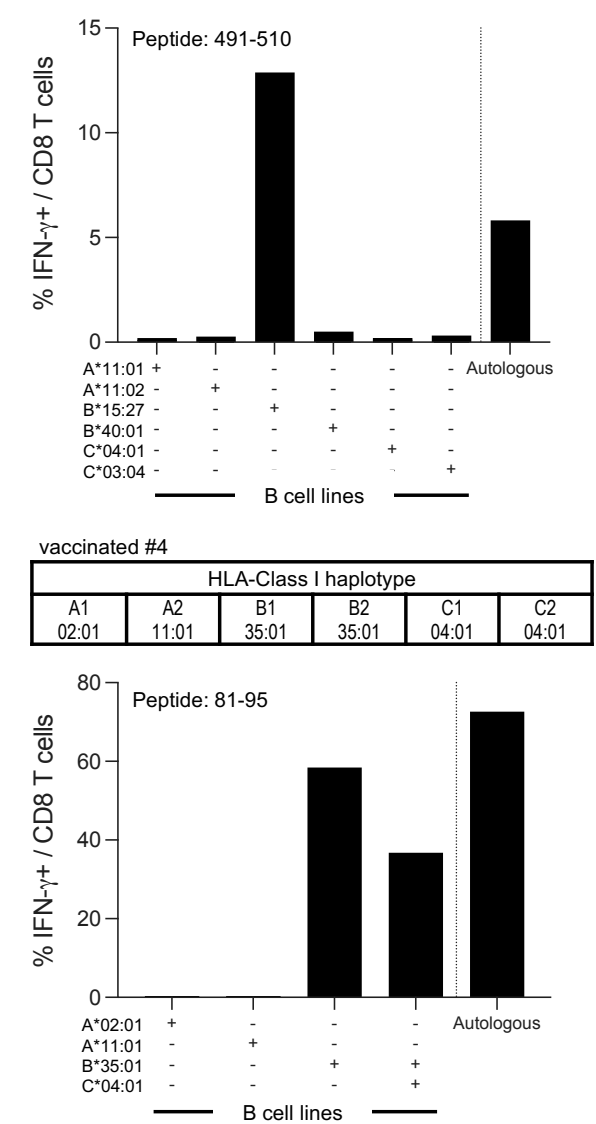

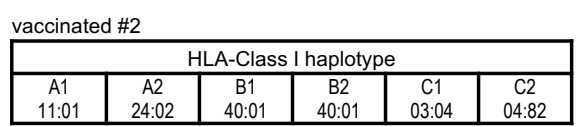

vaccinated \#3
\begin{tabular}{|c|c|c|c|c|c|}
\hline \multicolumn{6}{|c|}{ HLA-Class I haplotype } \\
\hline $\mathrm{A} 1$ & $\mathrm{~A} 2$ & $\mathrm{~B} 1$ & $\mathrm{~B} 2$ & $\mathrm{C} 1$ & $\mathrm{C} 2$ \\
$02: 05$ & $24: \mathrm{XX}$ & $35: 03$ & $50: 01$ & $06: 02$ & $12: 03$ \\
\hline
\end{tabular}
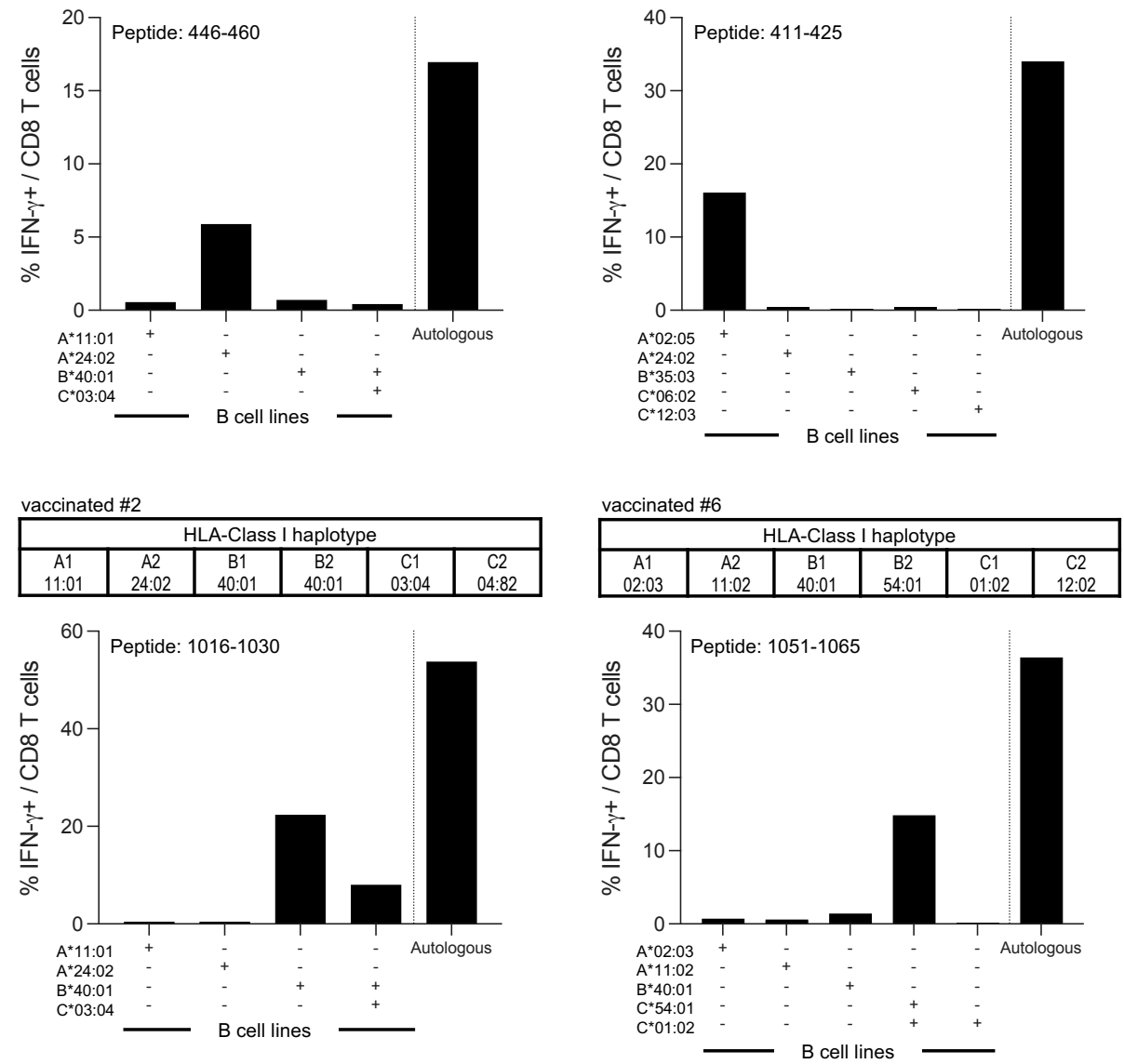

Figure S5: HLA-Class-I restriction of single-peptide specificities of 6 dominant CD8+ Spike-specific T cells The HLA-class I haplotypes of vaccinated donors 1, 2, 3, 4 are 6 are shown in the tables. HLA-restriction of the indicated peptide-specific $T$ cells from the donors was deduced by co-culturing the $T$ cells with peptide-pulsed EBVtransformed B cell lines that shared the indicated HLA-Class I molecule (+). Activation of the peptide-specific T cells by autologous cells was achieved by the direct addition of the peptide and used as a positive control. 


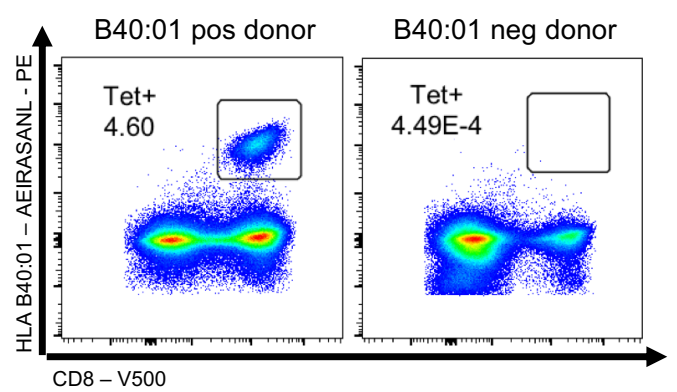

Figure S7: Definition of a CD8 T cell epitope in peptide S1016-30-specific T cells

S1016-30 expanded T cell lines of a HLA-B*40:01+ and a HLA-B*40:01- vaccine recipient were stained with HLA$B^{*} 40: 01$ tetramer containing peptide 1016-24. Dot plots show tetramer staining on CD3+ cells. 


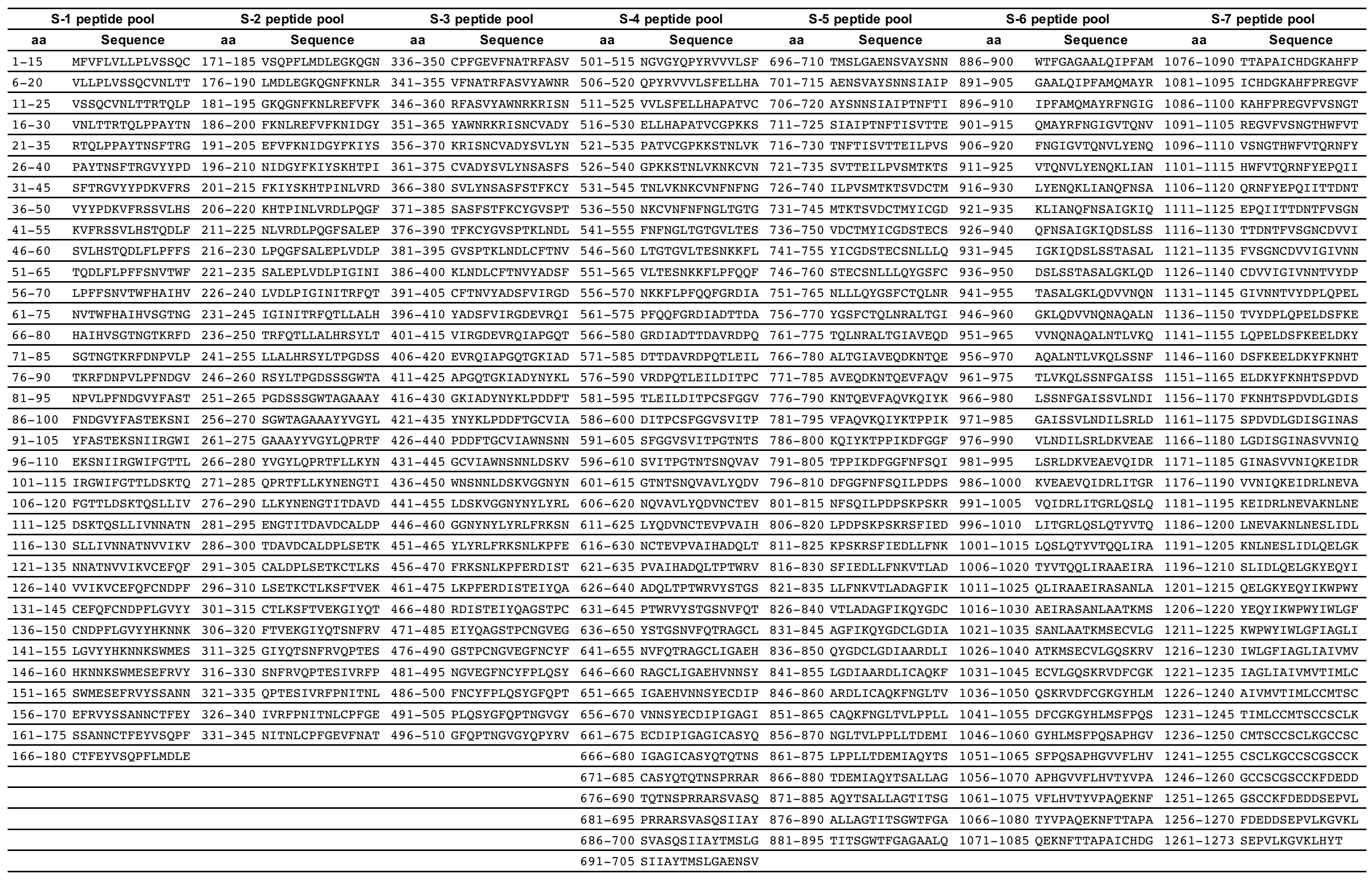


Table S2: Overlapping 15-mer peptides covering the region of the VOC mutations with and without the amino acid substitutions and deletions.

\begin{tabular}{|c|c|c|c|c|c|c|c|c|c|c|c|c|c|c|c|}
\hline \multicolumn{4}{|c|}{ Alpha } & \multicolumn{4}{|c|}{ Beta } & \multicolumn{4}{|c|}{ Gamma } & \multicolumn{4}{|c|}{ Delta } \\
\hline mutation & aa & Wuhan-Hu-1 & B.1.1.7 & mutation & аa & Wuhan-Hu-1 & B.1.351 & mutation & aa & Wuhan-Hu-1 & P.1 & mutation & aa & Wuhan-Hu-1 & B.1.617.2 \\
\hline \multirow{3}{*}{ del HV $69-70$} & $56-70$ & LPFFSNVTWFHAIHV & LPFFSNVTWFHAI-- & \multirow{3}{*}{ L18F } & $6-20$ & VLLPLVSSQCVNLTT & VLLPLVSSQCVNFTT & \multirow{3}{*}{ L18F T20N } & $6-20$ & VLLPLVSSQCVNLTT & VLLPLVSSQCVNFTN & \multirow{3}{*}{ T19R } & $6-20$ & VLLPLVSSQCVNLTT & VLLPLVSSQCVNLRT \\
\hline & $61-75$ & NVTWFHAIHVSGTNG & NVTWFHAI--SGTNG & & $11-25$ & VSSQCVNLTTRTQLP & VSSQCVNFTTRTQLP & & $11-25$ & VSSQCVNLTTRTQLP & VSSQCVNFTNRTQLP & & $11-25$ & VSSQCVNLTTRTQLP & VSSQCVNLRTRTQLP \\
\hline & $66-80$ & HAIHVSGTNGTKRFD & HAI--SGTNGTKRFD & & $16-30$ & VNLTTRTQLPPAYTN & VNFTTRTQLPPAYTN & & $16-30$ & VNLTTRTQLPPAYTN & VNFTNRTQLPPAYTN & & $16-30$ & VNLTTRTQLPPAYTN & VNLRTRTQLPPAYTN \\
\hline \multirow[t]{2}{*}{ del Y 144} & $136-150$ & CNDPFLGVYYHKNNK & CNDPFLGV-YHKNNK & \multirow[t]{2}{*}{ D80A } & 71-85 & SGTNGTKRFDNPVLP & SGTNGTKRFANPVLP & \multirow[t]{2}{*}{ P26S } & $21-35$ & RTQLPPAYTNSFTRG & RTQLPSAYTNSFTRG & \multirow[t]{2}{*}{ G142D } & $136-150$ & CNDPFLGVYYHKNNK & CNDPFLDVYYHKNNK \\
\hline & $141-155$ & LGVYYHKNNKSWMES & LGV-YHKNNKSWMES & & $76-90$ & TKRFDNPVLPFNDGV & TKRFANPVLPFNDGV & & $26-40$ & PAYTNSFTRGVYYPD & SAYTNSFTRGVYYPD & & $141-155$ & LGVYYHKNNKSWMES & LDVYYHKNNKSWMES \\
\hline \multirow{3}{*}{ N501Y } & 491-505 & PLQSYGFQPTNGVGY & PLQSYGFQPTYGVGY & \multirow{3}{*}{ D215G } & $201-215$ & FKIYSKHTPINLVRD & FKIYSKHTPINLVRG & \multirow{3}{*}{ D138Y } & $126-140$ & VVIKVCEFQFCNDPF & VVIKVCEFQFCNYPF & \multirow{3}{*}{ EFR156-8G } & $146-160$ & HKNNKSWMESEFRVY & HKNNKSWMESG--VY \\
\hline & $496-510$ & GFQPTNGVGYQPYRV & GFQPTYGVGYQPYRV & & $206-220$ & KHTPINLVRDLPQGF & KHTPINLVRGLPQGF & & $131-145$ & CEFOFCNDPFLGVYY & CEFOFCNYPFLGVYY & & $151-165$ & SWMESEFRVYSSANN & SWMESG--VYSSANN \\
\hline & 501-515 & NGVGYQPYRVVVLSF & YGVGYQPYRVVVLSF & & 211-225 & NLVRDLPQGFSALEP & NLVRGLPOGFSALEP & & $136-150$ & CNDPFLGVYYHKNNK & CNYPFLGVYYHKNNK & & $156-170$ & EFRVYSSANNCTFEY & G--VYSSANNCTFEY \\
\hline \multirow{3}{*}{ A570D } & $556-570$ & NKKFLPFQQFGRDIA & NKKFLPFQQFGRDID & \multirow{3}{*}{ del LLA 241-3 } & $231-245$ & IGINITRFQTLLALH & IGINITRFQT---LH & \multirow{3}{*}{ R190S } & $176-190$ & LMDLEGKQGNFKNLR & LMDLEGKQGNFKNLS & \multirow{3}{*}{ L452R } & $441-455$ & LDSKVGGNYNYLYRL & LDSKVGGNYNYRYRL \\
\hline & $561-575$ & PFQQFGRDIADTTDA & PFQQFGRDIDDTTDA & & $236-250$ & TRFQTLLALHRSYLT & TRFQT---LHRSYLT & & $181-195$ & GKQGNFKNLREFVFK & GKOGNFKNLSEFVFK & & $446-460$ & GGNYNYLYRLFRKSN & GGNYNYRYRLFRKSN \\
\hline & $566-580$ & GRDIADTTDAVRDPQ & GRDIDDTTDAVRDPQ & & $241-255$ & LLALHRSYLTPGDSS & ---LHRSYLTPGDSS & & $186-200$ & FKNLREFVFKNIDGY & FKNLSEFVFKNIDGY & & 451-465 & YLYRLFRKSNLKPFE & YRYRLFRKSNLKPFE \\
\hline \multirow{3}{*}{ D614G } & $601-615$ & GTNTSNQVAVLYQDV & GTNTSNQVAVLYQGV & \multirow{3}{*}{ K417N } & $406-420$ & EVRQIAPGQTGKIAD & EVRQIAPGQTGNIAD & \multirow{3}{*}{ K417T } & $406-420$ & EVRQIAPGQTGKIAD & EVRQIAPGQTGTIAD & \multirow{3}{*}{ T478K } & $466-480$ & RDISTEIYQAGSTPC & RDISTEIYQAGSKPC \\
\hline & $606-620$ & NOVAVLYQDVNCTEV & NOVAVLYOGVNCTEV & & $411-425$ & APGQTGKIADYNYKL & APGQTGNIADYNYKL & & $411-425$ & APGQTGKIADYNYKL & APGQTGTIADYNYKL & & 471-485 & EIYQAGSTPCNGVEG & EIYQAGSKPCNGVEG \\
\hline & $611-625$ & LYQDVNCTEVPVAIH & LYQGVNCTEVPVAIH & & $416-430$ & GKIADYNYKLPDDFT & GNIADYNYKLPDDFT & & $416-430$ & GKIADYNYKLPDDFT & GTIADYNYKLPDDFT & & $476-490$ & GSTPCNGVEGFNCYF & GSKPCNGVEGFNCYF \\
\hline & $671-685$ & CASYQTQTNSPRRAR & CASYQTQTNSHRRAR & & $471-485$ & EIYQAGSTPCNGVEG & EIYQAGSTPCNGVKG & & $471-485$ & EIYQAGSTPCNGVEG & EIYQAGSTPCNGVKG & & $601-615$ & GTNTSNQVAVLYQDV & GTNTSNQVAVLYQGV \\
\hline P681H & $676-690$ & TQTNSPRRARSVASQ & TQTNSHRRARSVASQ & E484K & $476-490$ & GSTPCNGVEGFNCYF & GSTPCNGVKGFNCYF & E484K & $476-490$ & GSTPCNGVEGFNCYF & GSTPCNGVKGFNCYF & D614G & $606-620$ & NQVAVLYQDVNCTEV & NQVAVLYQGVNCTEV \\
\hline & $681-695$ & PRRARSVASOSIIAY & HRRARSVASOSIIAY & & 481-495 & NGVEGFNCYFPLOSY & NGVKGFNCYFPLQSY & & 481-495 & NGVEGFNCYFPLQSY & NGVKGFNCYFPLQSY & & $611-625$ & LYQDVNCTEVPVAIH & LYOGVNCTEVPVAIH \\
\hline & $706-720$ & AYSNNSIAIPTNFTI & AYSNNSIAIPINFTI & & $491-505$ & PLQSYGFOPTNGVGY & PLQSYGFQPTYGVGY & & 491-505 & PLQSYGFOPTNGVGY & PLQSYGFOPTYGVGY & & $671-685$ & CASYQTOTNSPRRAR & CASYQTOTNSRRRAR \\
\hline & 971-985 & GAISSVLNDILSRLD & GAISSVLNDILARLD & & $601-615$ & GTNTSNQVAVLYQDV & GTNTSNOVAVLYQGV & & 601-615 & GTNTSNQVAVLYQDV & GTNTSNOVAVLYQGV & & $936-950$ & DSLSSTASALGKLQD & DSLSSTASALGKLND \\
\hline S982A & $976-990$ & VLNDILSRLDKVEAE & VLNDILARLDKVEAE & D614G & $606-620$ & NOVAVLYQDVNCTEV & NOVAVLYOGVNCTEV & D614G & $606-620$ & NOVAVLYQDVNCTEV & NOVAVLYQGVNCTEV & D950N & 941-955 & TASALGKLQDVVNON & TASALGKLQNVVNON \\
\hline & 981-995 & LSRLDKVEAEVQIDR & LARLDKVEAEVQIDR & & $611-625$ & LYQDVNCTEVPVAIH & LYOGVNCTEVPVAIH & & $611-625$ & LYQDVNCTEVPVAIH & LYOGVNCTEVPVAIH & & $946-960$ & GKLQDVVNONAQALN & GKLQNVVNONAQALN \\
\hline & $1106-1120$ & QRNFYEPQIITTDNT & QRNFYEPQIITTHNT & & $691-705$ & SIIAYTMSLGAENSV & SIIAYTMSLGVENSV & & $641-655$ & NVFQTRAGCLIGAEH & NVFQTRAGCLIGAEY & & & & \\
\hline $\mathrm{D} 1118 \mathrm{H}$ & $1111-1125$ & EPQIITTDNTFVSGN & EPQIITTHNTFVSGN & A701V & 696-710 & TMSLGAENSVAYSNN & TMSLGVENSVAYSNN & $\mathrm{H} 655 \mathrm{Y}$ & $646-660$ & RAGCLIGAEHVNNSY & RAGCLIGAEYVNNSY & & & & \\
\hline & $1116-1130$ & TTDNTFVSGNCDVVI & TTHNTFVSGNCDVVI & & 701-715 & AENSVAYSNNSIAIP & VENSVAYSNNSIAIP & & $651-665$ & IGAEHVNNSYECDIP & IGAEYVNNSYECDIP & & & & \\
\hline & & & & & & & & & 1016-1030 & AEIRASANLAATKMS & AEIRASANLAAIKMS & & & & \\
\hline & & & & & & & & T10271 & 1021-1035 & SANLAATKMSECVLG & SANLAAIKMSECVLG & & & & \\
\hline & & & & & & & & & $1026-1040$ & ATKMSECVLGQSKRV & AIKMSECVLGQSKRV & & & & \\
\hline & & & & & & & & & $1166-1180$ & LGDISGINASVVNIQ & LGDISGINASFVNIQ & & & & \\
\hline & & & & & & & & V1176F & $1171-1185$ & GINASVVNIQKEIDR & GINASFUNIQKEIDR & & & & \\
\hline & & & & & & & & & $1176-1190$ & VVNIQKEIDRLNEVA & FVNIOKEIDRLNEVA & & & & \\
\hline
\end{tabular}


Table S3: Spike mutations in VOCs vs Wuhan-Hu1. Grey highlighted mutations were tested in this manuscript.

\begin{tabular}{|c|c|c|c|c|c|}
\hline & Alpha & Beta & Gamma & Delta & Omicron \\
\hline & B1.1.7 & B1.351 & P.1 & B.1.617.2 & B.1.1.529 \\
\hline L18F & & $(F)$ & $\mathrm{F}$ & & \\
\hline T19R & & & & $\mathrm{R}$ & \\
\hline T20N & & & $\mathrm{N}$ & & \\
\hline P26S & & & $\mathrm{S}$ & & \\
\hline A67V & & & & & $\mathrm{V}$ \\
\hline del $69-70$ & del & & & & del \\
\hline D80A & & $\mathrm{A}$ & & & \\
\hline T95I & & & & (I) & 1 \\
\hline D138Y & & & $Y$ & & \\
\hline G142D & & & & (D) & $\mathrm{D}$ \\
\hline del $143-5$ & & & & & del \\
\hline del 144 & del & & & & \\
\hline E156G & & & & $\mathrm{G}$ & \\
\hline del 157-8 & & & & del & \\
\hline R190S & & & $S$ & & \\
\hline N211I & & & & & 1 \\
\hline del 212 & & & & & del \\
\hline ins EPE 214 & & & & & ins \\
\hline D215G & & $\mathrm{G}$ & & & \\
\hline del 241-3 & & del & & & \\
\hline G339D & & & & & $D$ \\
\hline S371L & & & & & $\mathrm{L}$ \\
\hline S373P & & & & & $\mathrm{P}$ \\
\hline S375F & & & & & $\mathrm{F}$ \\
\hline K417N/T & & $\mathrm{N}$ & $\mathrm{T}$ & & $(\mathrm{N})$ \\
\hline L452R & & & & $\mathrm{R}$ & \\
\hline S477N & & & & & $\mathrm{N}$ \\
\hline T478K & & & & $\mathrm{K}$ & $\mathrm{K}$ \\
\hline E484A/K & & $\mathrm{K}$ & $\mathrm{K}$ & & $A$ \\
\hline Q493R & & & & & $\mathrm{R}$ \\
\hline G496S & & & & & $S$ \\
\hline Q498R & & & & & $\mathrm{R}$ \\
\hline N501Y & $Y$ & $Y$ & $Y$ & & $Y$ \\
\hline $\mathrm{Y} 505 \mathrm{H}$ & & & & & $\mathrm{H}$ \\
\hline T547K & & & & & $\mathrm{K}$ \\
\hline A570D & $\mathrm{D}$ & & & & \\
\hline D614G & $\mathrm{G}$ & $\mathrm{G}$ & $\mathrm{G}$ & $\mathrm{G}$ & $\mathrm{G}$ \\
\hline $\mathrm{H} 655 \mathrm{Y}$ & & & $Y$ & & $Y$ \\
\hline N679K & & & & & $\mathrm{K}$ \\
\hline $\mathrm{P} 681 \mathrm{R} / \mathrm{H}$ & $\mathrm{H}$ & & & $\mathrm{R}$ & $\mathrm{H}$ \\
\hline A701V & & $\mathrm{V}$ & & & (V) \\
\hline T716I & 1 & & & & \\
\hline D796Y & & & & & $Y$ \\
\hline N856K & & & & & $\mathrm{K}$ \\
\hline D950N & & & & $\mathrm{N}$ & \\
\hline $\mathrm{Q} 954 \mathrm{H}$ & & & & & $\mathrm{H}$ \\
\hline N969K & & & & & $\mathrm{K}$ \\
\hline L981F & & & & & $\mathrm{F}$ \\
\hline S982A & $\mathrm{A}$ & & & & \\
\hline T1027I & & & 1 & & \\
\hline $\mathrm{D} 1118 \mathrm{H}$ & $\mathrm{H}$ & & & & \\
\hline V1176F & & & $\mathrm{F}$ & & \\
\hline
\end{tabular}

